\title{
Estimation of Radiation Doses and Lifetime Attributable Risk of Radiation-induced Cancer from A Single Coronary Artery Bypass Graft Computed Tomography Angiography
}

\author{
Husam H Mansour ${ }^{1,2 \star}$, Yasser S Alajerami ${ }^{2}$, Thomas Foster ${ }^{3}$
}

\author{
${ }^{1}$ Radiology Department, Al-Shifa Hospital, Gaza, PALESTINE \\ ${ }^{2}$ Medical Imaging Department, Al-Azhar University, PALESTINE \\ ${ }^{3}$ Department of Imaging Sciences, University of Rochester, Rochester, NY, USA \\ *Corresponding Author: husam-rt2007@hotmail.com
}

Citation: Mansour HH, Alajerami YS, Foster T. Estimation of Radiation Doses and Lifetime Attributable Risk of Radiation-induced Cancer from A Single Coronary Artery Bypass Graft Computed Tomography Angiography. Electron J Gen Med. 2021;18(6):em317. https://doi.org/10.29333/ejgm/11208

\section{ARTICLE INFO}

Received: 1 Jun. 2021

Accepted: 1 Aug. 2021

\begin{abstract}
Introduction: Despite worldwide consensus that coronary artery bypass graft computed tomography angiography (CABG CTA) confers benefit to patients when used for appropriate indications, the increased cancer risk due to radiation dose remains a concern. The aim of this study is the estimation of organ effective dose (ED) and lifetime attributable risk (LAR) of cancer incidence and mortality related to a single CABG CTA procedure.

Methods and materials: This retrospective cross-sectional designed study included 102 CABG patients who, from January 2021 to June 2021, underwent a retrospective 64-slice ECG-gated CABG CTA covering the area of the grafts with optimal image quality. The estimation of ED was done using the imPACT CT Dosimetry spreadsheet. LAR of cancer incidence was estimated for CABG CTA using the website X-rayrisk.com.
\end{abstract}

Results: The mean total ED of CABG procedure was $15.35 \mathrm{mSv}$. The highest organ doses were those to the lungs $(5.04 \mathrm{mSv}$ ) and breast (4.49 mSv). The cancer risk is higher in female (1 in 1516) than in male patients (1 in 1762). The LAR of cancer is higher for the younger age group in both males and females. The total whole-body ED demonstrated that CABG CTA is equivalent to 154 chest radiographs or 37 screening mammography studies, which in turn correspond to approximately 4.3 or 5 -years of natural background radiation, respectively.

Conclusions: Despite many benefits of CABG CTA, it is associated with a non-negligible risk of malignancy, so a careful risk/benefit assessment is recommended in justifying CABG CTA procedures, especially for young female patients.

Keywords: attributable risk of radiation-induced cancer, coronary artery bypass graft computed tomography angiography, estimation of radiation doses

\section{INTRODUCTION}

The application of ionizing radiation is increasing dramatically in medical imaging, driven primarily by the increased use of x-ray Computed Tomography (CT). Medical procedures are now responsible for approximately one-half of the ionizing radiation exposure to the human population $[1,2]$ Diagnostic imaging protocols based on multidetector computed tomography (MDCT) are widely used [3].

Organ doses from conventional radiography are significantly smaller than those associated with MDCT [4]. Consequently, MDCT scans are the dominant contributor to the collective dose from medical radiation sources [5,6]. Concomitant with the technological advances of MDCT, coronary computed tomographic coronary angiography (CCTA) has emerged as a non-invasive, patient-friendly diagnostic modality to detect the presence of coronary atherosclerosis [7].
Plentiful studies have demonstrated that CCTA has high diagnostic accuracy in the proper evaluation of the patency of coronary artery bypass graft (CABG) cases compared with invasive coronary angiography (ICA) and performs even better than an assessment of native coronaries [8-10]. The exceptional image quality of CCTA must be weighed against its associated radiation exposure [3]. It has been reported that CT scans currently contribute $75 \%$ of the collective radiation dose given to patients in a radiology department [11].

Although several estimates of CCTA radiation doses have been reported [12], there is little data addressing organ dose and the relationship between radiation dose and cancer risk in patients undergoing CCTA examinations [13]. Although several studies focused on the calculation of the effective dose associated with CCTA $[14,15]$, the effective dose does not consider the age of the patients, which is considered an essential variable in determining the radiation risk [16-18]. Radiation-induced cancer has been related to radiation exposure. Consequently, the possible increased cancer risk has become an important concern related to CCTA and especially 
in CABG CTA [19]. A recent study by Mansour et al. [20] comparing the utility of CCTA and ICA revealed that $4.8 \%$ of patients diagnosed with ICA versus $38.9 \%$ of patients diagnosed with CCTA had CABG. Furthermore, this study revealed that the mean radiation dose of patients diagnosed with CCTA was $11.589 \mathrm{mSv}$, but the study did not explore cancer risk from CABG CTA.

The life attributable risk (LAR) of cancer incidence and mortality describes an excess of disease cases relative to a background rate of an age-matched unexposed population [21]. In the current study, we aimed to evaluate radiation doses received by $C A B G$ patients who had undergone retrospective ECG-gated CCTA, and we estimated the LAR of radiationinduced cancer incidence and mortality among this patient group.

\section{MATERIALS AND METHODS}

\section{Patient Selection}

For our retrospective cross-sectional designed study, 102 consecutive CABG patients who underwent a successful retrospective 64-slice ECG-gated CCTA protocol were recruited during the study period from January 2021 to June 2021. Inclusion criteria were based on technical factors that rendered CABG CTA optimal image quality and covered the area of the grafts. All CABG CTA that did not match the inclusion criteria were excluded from the study.

ECG-triggered dose modulation delivered the highest tube current during $40 \%$ to $80 \%$ of the RR interval. Data collection included patient characteristics, scan protocol parameters, scan time, beginning and end table positions, patient heart rate, tube voltage, maximum and mean effective mAs, volume, collimation, pitch, gantry rotation time, CT dose index (CTDIvol), and dose-length product (DLP). The study was fully approved by the local hospital ethics committee.

\section{CCTA Acquisition Parameters}

CT examinations were performed using the 64-slice Siemens SOMATOM Definition AS. Standard scan parameters were used: modulated tube current $(\mathrm{mA})$ range was $178-320$ $\mathrm{mA}$, a tube voltage of $120 \mathrm{kVp}$, collimation $64 \times 0.6 \mathrm{~mm}$, pitch 0.2 , and gantry rotation time $0.33 \mathrm{~s}$. The CCTA scan for patients with CABG was performed craniocaudal with scan range between the top of the lung apices and extending to the inferior margin of the heart to include the entire heart and the ligation of the grafts. The patients were instructed to hold their breath during the scan acquisition. Automatic tube current modulation and automatic ECG-pulsing were used to reduce radiation exposure.

\section{Effective Dose Estimation}

The estimation of CT organ dose was done using the imPACT CT Dosimetry spreadsheet, a tool for calculating patient organ and effective doses from CT scanner examinations. It makes use of the National Radiological Protection Board (NRPB) Monte Carlo dose data sets produced in report SR250 (Health Protection Agency Centre for Radiation, Chemical and Environmental Hazards, Didcot, UK). SR250 provides normalized organ dose data for irradiation of a model medical internal radiation dose (MIRD) phantom by a range of CT scanners. Organ doses were calculated on the basis of the tissue weighting factors of the International Commission

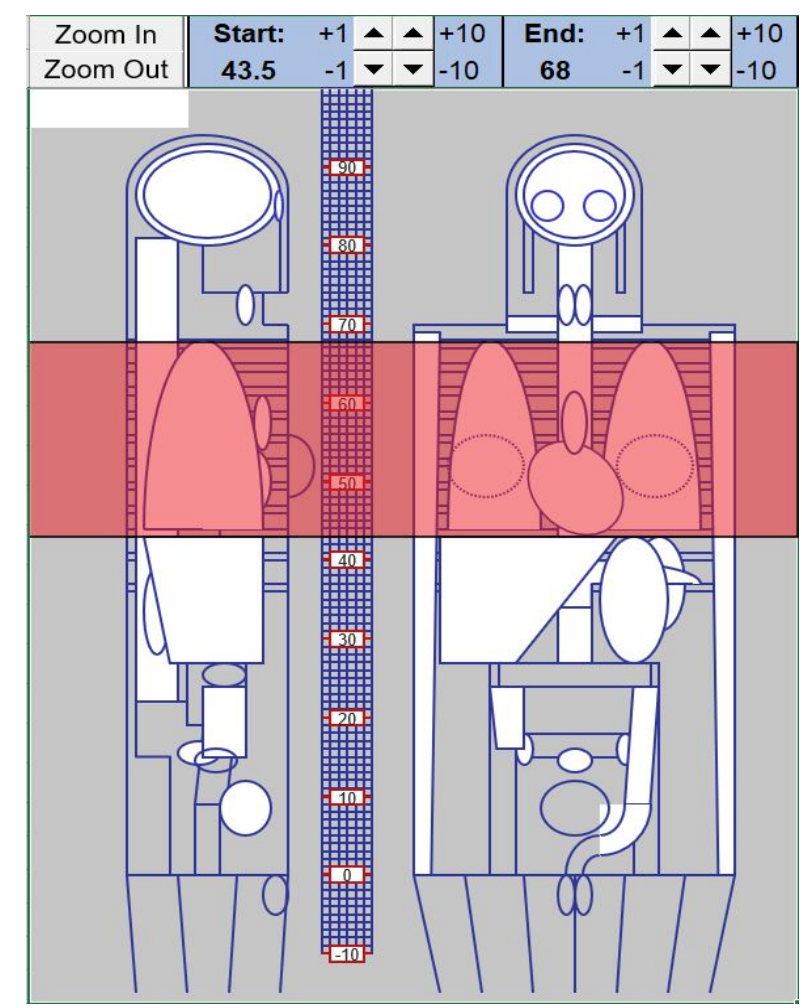

Figure 1. An adult, hermaphrodite, model phantom

on Radiation Protection (ICRP) report 103. The focus was to estimate CT organ dose using an adult, hermaphrodite, model phantom (Figure 1).

The imPACT CT Dosimetry spreadsheet is based on Monte Carlo Data Set with pre-calculated Computed Tomography Dose Index measurements in free air (CTDI100), center (CTDI100, C) and peripheries (CTDI100, P) that had been measured in a standard Perspex head and body dosimetry phantom, using the same ionization chamber and a consistent technique that have proven to be good for most of the CT scanners used. These measurements in turn are useful for calculation of the weighted CTDI (CTDIw), volume CTDI (CTDIvol), DLP and other dose parameters (Figure 2). Parameters that were inputted manually into the CT Dosimetry spreadsheet were the tube current, rotation time and spiral pitch, which vary with protocol and from vendor to vendor.

\section{Estimates of Lifetime Attributable Risk of Cancer}

Lifetime attributable risk (LAR) of cancer incidence and mortality was estimated for CABG CTA using the website Xrayrisk.com (Figure 3 ), which, in addition to being an educational site, contains a web-based calculator that allows estimation of the LAR of cancer based on the body-region scanned, age, gender, and average dose for a given patient. The LAR of cancer incidence and mortality is defined as additional cancer risk above and beyond baseline cancer risk.

\section{Statistical Analysis}

Data were analyzed using IBM SPSS version 25 (IBM Corporation, Armonk, New York, USA). The KolmogorovSmirnov Test was used to determine the normality of the estimated effective dose. The quantitative variables were expressed as a mean \pm standard deviation. Pearson $(r)$ was computed to assess the correlation of the estimate of the LAR of cancer incidence and effective dose. A value of $p<0.05$ was considered statistically significant. 


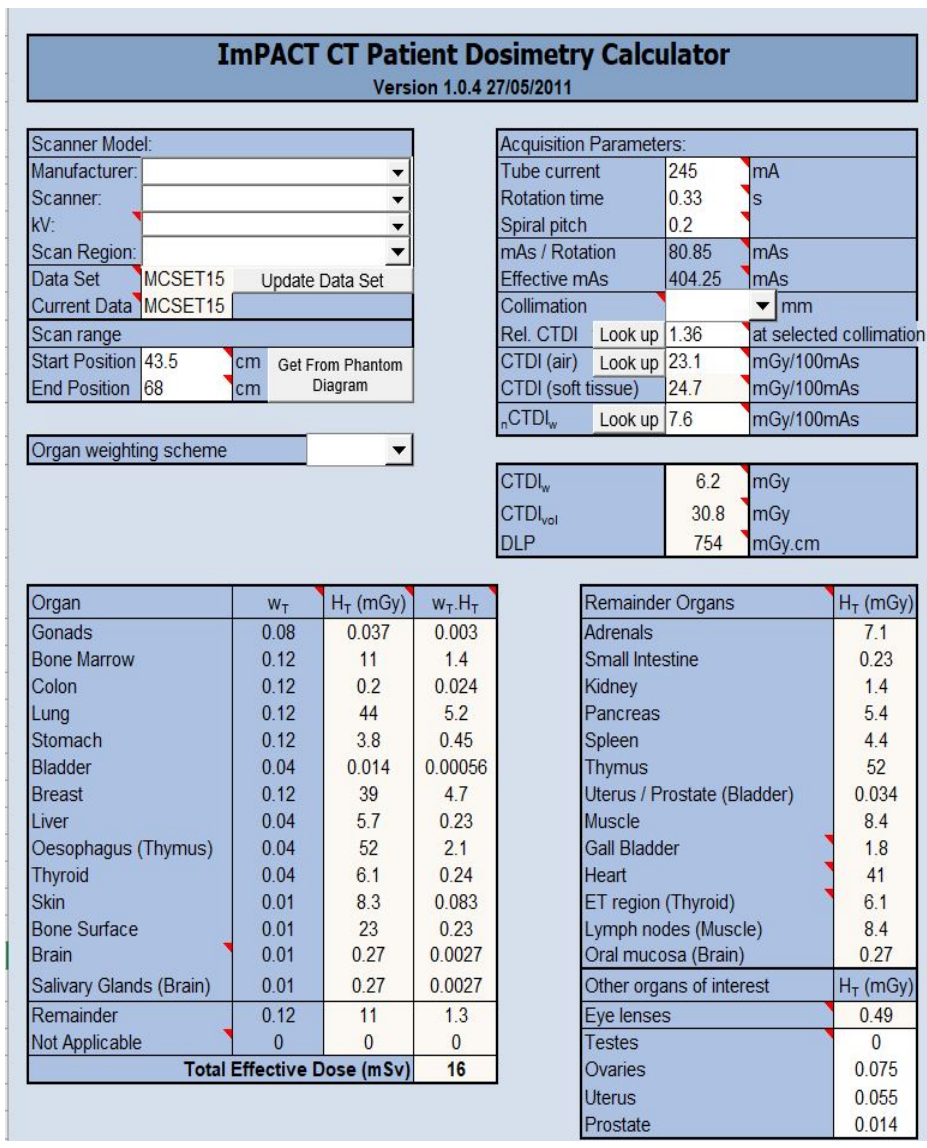

Figure 2. An overview of the imPACT CT dosimetry spreadsheet

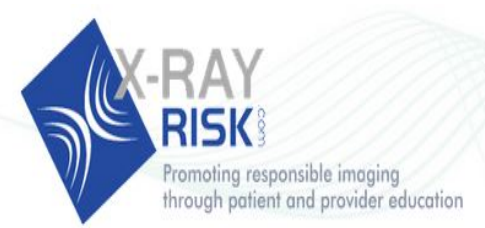

FAQ of the Month

Top 5 Ways to Decrease your Exposure to Medical
Radíation

NOW AVAILABLE

FREE DOWNLOAD:Patient Radiation Handout

\begin{tabular}{|c|c|c|c|c|}
\hline home & about & fag's & calculate your risk & glossary \\
\hline
\end{tabular}

\begin{tabular}{|l|}
\hline Plain Films (x-rays) \\
\hline Chest $x$-ray (2 views) \\
Abdomen $x$-rays \\
Pelvis $x$-rays \\
Hip x-rays (unilateral) \\
Neck $x$-rays \\
Upper Back $x$-rays \\
Lower Back x-rays \\
Extremity x-rays (Hands, Feet, etc) \\
Mammogram (unilateral) \\
Dental x-ray (panoramic) \\
Dental x-ray (4 intraoral bitewings) \\
Skull $x$-rays \\
DEXA Scan (Bone Density) \\
Dose is based on multiple views \\
\hline CT Scans \\
\hline Fluoroscopy \\
\hline Nuclear Medicine \\
\hline Interventional Procedures \\
\hline MRI and Ultrasound \\
\hline
\end{tabular}

Study:

Gender:

Age at Time of Study:

Number of Exams:

Effective Dose:

DLP (Optional for CT):

Cardiac CT (Coronary CT)

Male 0 Female 0

60 (years)

16.000 (mSv)

Optional (mGy $\cdot \mathrm{cm})$

Calculate Add This Exam to your Report

\begin{tabular}{|c|c|c|c|}
\hline Total Effective Dose: & 16 & $(\mathrm{mSv}$ & \\
\hline Additional Cancer Risk: & $0.06145 t$ & $(\%)$ & 1 in 1627 \\
\hline Baseline Cancer Risk: & 44.9 & $(\%)$ & \\
\hline Baseline + Additional Risk: & 44.9614! & $(\%)$ & \\
\hline
\end{tabular}

Add This Exam to your Report

To learn more about how these calculations are made, see the About page.

Figure 3. The website X-ray risk Calculator 
Table 1. Image acquisition parameters.

\begin{tabular}{|c|c|c|c|c|c|c|}
\hline Parameters & Gender & $\mathbf{N}$ & Minimum & Maximum & Mean & Std. Deviation \\
\hline & Male & 62 & 178 & 320 & 240.66 & 41.073 \\
\hline \multirow[t]{2}{*}{$\mathbf{m A}$} & Female & 40 & 178 & 280 & 227.85 & 32.596 \\
\hline & All & 102 & 178 & 320 & 235.64 & 38.323 \\
\hline \multirow{3}{*}{ Acquisition Time } & Male & 62 & 11 & 12.5 & 11.56 & 0.524 \\
\hline & Female & 40 & 11 & 12.5 & 11.83 & 0.583 \\
\hline & All & 102 & 11 & 12.5 & 11.67 & 0.560 \\
\hline \multirow{3}{*}{ CTDIw } & Male & 62 & 4.5 & 8 & 6.01 & 1.042 \\
\hline & Female & 40 & 4.5 & 7 & 5.75 & 0.844 \\
\hline & All & 102 & 4.5 & 8 & 5.91 & 0.974 \\
\hline \multirow{3}{*}{ CTDIvol (mGy) } & Male & 62 & 22.60 & 40.20 & 30.09 & 5.189 \\
\hline & Female & 40 & 22.60 & 34.80 & 28.76 & 4.156 \\
\hline & All & 102 & 22.60 & 40.20 & 29.57 & 4.829 \\
\hline \multirow{3}{*}{ DLP $\left(\mathrm{mGy}^{\star} \mathrm{cm}\right)$} & Male & 62 & 554 & 985 & 737.34 & 126.535 \\
\hline & Female & 40 & 554 & 852 & 704.55 & 101.202 \\
\hline & All & 102 & 554 & 985 & 724.48 & 117.829 \\
\hline
\end{tabular}

Table 2. Effective and organ doses estimations during CABG CTA procedure

\begin{tabular}{|c|c|c|c|c|c|c|}
\hline Organ & Gender & $\mathbf{N}$ & Minimum & Maximum & Mean & Std. Deviation \\
\hline & Male & 62 & 0.0022 & 0.0039 & 0.0029 & 0.0005 \\
\hline \multirow[t]{3}{*}{ Gonads } & Female & 40 & 0.0022 & 0.0034 & 0.0028 & 0.0004 \\
\hline & All & 102 & 0.0022 & 0.0039 & 0.0029 & 0.0005 \\
\hline & Male & 62 & 1.00 & 1.80 & 1.35 & 0.236 \\
\hline \multirow[t]{3}{*}{ Bone marrow } & Female & 40 & 1.00 & 1.60 & 1.30 & 0.209 \\
\hline & All & 102 & 1.00 & 1.80 & 1.33 & 0.226 \\
\hline & Male & 62 & 0.018 & 0.031 & 0.0237 & 0.0040 \\
\hline \multirow[t]{3}{*}{ Colon } & Female & 40 & 0.018 & 0.027 & 0.0226 & 0.0032 \\
\hline & All & 102 & 0.018 & 0.031 & 0.0233 & 0.0037 \\
\hline & Male & 62 & 3.90 & 6.90 & 5.1323 & 0.8809 \\
\hline \multirow[t]{3}{*}{ Lung } & Female & 40 & 3.90 & 5.90 & 4.9000 & 0.6921 \\
\hline & All & 102 & 3.90 & 6.90 & 5.0412 & 0.8165 \\
\hline & Male & 62 & 0.33 & 0.59 & 0.4427 & 0.07629 \\
\hline \multirow[t]{3}{*}{ Stomach } & Female & 40 & 0.33 & 0.51 & 0.4228 & 0.06093 \\
\hline & All & 102 & 0.33 & 0.59 & 0.4349 & 0.07103 \\
\hline & Male & 62 & 0.00041 & 0.00073 & 0.00054 & 0.00009 \\
\hline \multirow[t]{3}{*}{ Bladder } & Female & 40 & 0.00041 & 0.00063 & 0.00052 & 0.00008 \\
\hline & All & 102 & 0.00041 & 0.00073 & 0.00053 & 0.00009 \\
\hline & Male & 62 & 3.40 & 5.30 & 4.37 & 0.652 \\
\hline \multirow[t]{2}{*}{ Breast } & Female & 40 & 3.40 & 6.10 & 4.57 & 0.806 \\
\hline & All & 102 & 3.40 & 6.10 & 4.49 & 0.753 \\
\hline \multirow{3}{*}{ Liver } & Male & 62 & 0.17 & 0.30 & 0.22 & 0.038 \\
\hline & Female & 40 & 0.17 & 0.26 & 0.21 & 0.030 \\
\hline & All & 102 & 0.17 & 0.30 & 0.22 & 0.035 \\
\hline
\end{tabular}

\section{RESULTS}

\section{Demographic Characteristics}

Gender distribution in the CABG patients showed that there were $62(60.8 \%)$ male and $40(39.2 \%)$ female. The age of patients ranged from 45 to 75 years (mean $\pm S D=60.1 \pm 7.56$ ).

\section{Image Acquisition Parameters}

Standard image acquisition parameters such as tube voltage of $120 \mathrm{kVp}$, collimation $64 \times 0.6 \mathrm{~mm}$, pitch 0.2 and gantry rotation time $0.33 \mathrm{~s}$ were constant for all CABG patients. Image acquisition parameters that were varied according to the patient's status are summarized in Table 1. These include: tube current, acquisition time, CTDIw, CTDIvol, and DLP.

\section{Correlation between $\mathrm{mA}$, Acquisition Time and DLP $\left(\mathrm{mGy}{ }^{\star} \mathrm{cm}\right)$}

The Pearson Correlation ( $r$ ) shows a statistically significant, strong, positive correlation between $\mathrm{mA}$ and $\mathrm{DLP}\left(\mathrm{mGy}^{*} \mathrm{~cm}\right)(\mathrm{r}$
$=0.989$ ). Moreover, the Pearson Correlation ( $r$ ) shows a statistically significant, moderate, positive correlation between acquisition time and DLP $\left(\mathrm{mGy}^{*} \mathrm{~cm}\right)(\mathrm{r}=0.621)$.

\section{Effective and Organ Dose Estimations During CABG CTA Procedure}

The organ equivalent dose (mSv) is estimated by the imPACT CT Dosimetry spreadsheet and given by wT.HT, where (wT) indicates tissue weighting factors given in ICRP publication 103 and $(\mathrm{HT})$ is the absorbed radiation dose to the organ (mGy). The Total Effective Dose (mSv) associated with the CABG procedure ranged from $12 \mathrm{mSv}$ to $21 \mathrm{mSv}$ (mean $\pm \mathrm{SD}$ $=15.35 \pm 2.428$ ). The highest organ doses were those to the lungs (mean weighted equivalent dose $5.04 \pm 0.82$ (3.9-6.9) $\mathrm{mSv}$ ) and breast (mean $4.49 \pm 0.75$ (3.4-6.1) $\mathrm{mSv}$ ). These were followed by the esophagus $(2.0 \pm 0.35(1.5-2.7) \mathrm{mSv})$, bone marrow (1.33 \pm $0.23(1-1.8) \mathrm{mSv})$, and stomach (0.44 $\pm 0.07(0.33-0.59) \mathrm{mSv})$ as shown in Table 2. 
Table 2 (continued). Effective and organ doses estimations during CABG CTA procedure

\begin{tabular}{|c|c|c|c|c|c|c|}
\hline Organ & Gender & $\mathbf{N}$ & Minimum & Maximum & Mean & Std. Deviation \\
\hline \multirow{3}{*}{ Esophagus } & Male & 62 & 1.50 & 2.70 & 2.04 & 0.368 \\
\hline & Female & 40 & 1.50 & 2.40 & 1.94 & 0.302 \\
\hline & All & 102 & 1.5 & 2.70 & 2.00 & 0.345 \\
\hline \multirow{3}{*}{ Thyroid } & Male & 62 & 0.18 & 0.32 & 0.237 & 0.041 \\
\hline & Female & 40 & 0.18 & 0.27 & 0.226 & 0.032 \\
\hline & All & 102 & 0.18 & 0.32 & 0.233 & 0.038 \\
\hline \multirow{3}{*}{ Skin } & Male & 62 & 0.061 & 0.110 & 0.081 & 0.015 \\
\hline & Female & 40 & 0.061 & 0.093 & 0.077 & 0.011 \\
\hline & All & 102 & 0.061 & 0.110 & 0.080 & 0.013 \\
\hline \multirow{3}{*}{ Bone surface } & Male & 62 & 0.17 & 0.31 & 0.230 & 0.041 \\
\hline & Female & 40 & 0.17 & 0.27 & 0.220 & 0.033 \\
\hline & All & 102 & 0.17 & 0.31 & 0.226 & 0.038 \\
\hline \multirow{3}{*}{ Brain } & Male & 62 & 0.0020 & 0.0035 & 0.0027 & 0.0005 \\
\hline & Female & 40 & 0.0020 & 0.0031 & 0.0026 & 0.0004 \\
\hline & All & 102 & 0.0020 & 0.0035 & 0.0026 & 0.0004 \\
\hline \multirow{3}{*}{ Salivary gland } & Male & 62 & 0.0020 & 0.0035 & 0.0027 & 0.0005 \\
\hline & Female & 40 & 0.0020 & 0.0031 & 0.0026 & 0.0004 \\
\hline & All & 102 & 0.0020 & 0.0035 & 0.0026 & 0.0004 \\
\hline \multirow{3}{*}{ "Remainder Organs } & Male & 62 & 0.93 & 1.70 & 1.227 & 0.214 \\
\hline & Female & 40 & 0.93 & 1.40 & 1.168 & 0.162 \\
\hline & All & 102 & 0.93 & 1.70 & 1.203 & 0.197 \\
\hline \multirow{3}{*}{ Total Effective Dose (mSv) } & Male & 62 & 12 & 21 & 15.61 & 2.607 \\
\hline & Female & 40 & 12 & 18 & 14.95 & 2.087 \\
\hline & All & 102 & 12 & 21 & 15.35 & 2.428 \\
\hline
\end{tabular}

Remainder Organs: Adrenals, Small Intestine, Kidney, Pancreas, Spleen, Gall Bladder, Thymus, Muscle, Heart, Lymph nodes, Oral mucosa, Eye lenses, Uterus, Ovaries, Prostate and Testes

Table 3. Comparison of LAR of cancer for male and female patients regarding age group

\begin{tabular}{|c|c|c|c|c|c|}
\hline \multirow{2}{*}{ Age group } & \multirow{2}{*}{ Gender } & \multicolumn{4}{|c|}{ LAR of cancer } \\
\hline & & $\mathrm{N}=102$ & Mean (\%) & Std. Deviation & (1 in) \\
\hline \multirow{2}{*}{$45 y$ to $55 y$} & Male & 22 & 0.000713 & 0.0001125 & 1447 Male \\
\hline & Female & 12 & 0.000926 & 0.0001799 & 1114 Female \\
\hline \multirow{2}{*}{$56 y$ to $65 y$} & Male & 22 & 0.000624 & 0.0001205 & 1658 Male \\
\hline & Female & 18 & 0.000749 & 0.0001078 & 1362 Female \\
\hline \multirow{2}{*}{$66 y$ to $75 y$} & Male & 18 & 0.000476 & 0.0009405 & 2181 Male \\
\hline & Female & 10 & 0.000496 & 0.0008718 & 2073 Female \\
\hline \multirow{3}{*}{ All Age groups } & Male & 62 & 0.000613 & 0.000146 & 1762 Male \\
\hline & Female & 40 & 0.000739 & 0.000205 & 1516 Female \\
\hline & All & 102 & 0.000662 & 0.000183 & 1639 Patient \\
\hline
\end{tabular}

Comparison of LAR of Cancer for Male and Female Patients Regarding Age Group

The Pearson Correlation ( $r$ ) shows a statistically significant negative correlation between age and LAR $(r=0.718)$. The average value of LAR of cancer for all CABG patients is 1 in 1639 patients who underwent CABG CTA. The cancer risk is higher for female patients ( 1 in 1516 females who underwent CABG CTA) than male patients ( 1 in 1762 males who underwent CABG CTA). The LAR of cancer is higher for the younger age group in both males and females as shown in Table 3.

\section{DISCUSSION}

Despite the great medical benefits derived from advances in $\mathrm{MDCT}$, the increased radiation dose presents a potential future cancer risk. Requests for CCTA examinations have increased. However, medical staffs may not have adequate knowledge of the risks of the ionizing radiation used in these procedures. CABG CTA examinations have risks potentially greater than CCTA due to an increased scan range. Risk of cancer incidence and mortality from ionizing radiation are appropriately expressed in terms of LAR values. In general, the use of radiation doses as low as reasonably achievable consistent with acceptable image quality remains the most significant strategy for diminishing this potential risk.

Previously published estimations of organ dose were often carried out using a specific scan parameter such as a limited range of tube current, heart rate, or a specific range of patient ages. In the current study, as described in Materials and Methods, the calculation of organ dose in the ImPACT CT was based on CTDIvol, so that the effect of all relevant variables, such as the tube current, pitch factor, automatic exposure control (AEC) and heart rate have been considered [22,23].

Although some scan parameters were fixed (120 kVp, collimation $64 \times 0.6 \mathrm{~mm}$, pitch 0.2 and gantry rotation time 0.33), the variable scan parameters ( $\mathrm{mA}$, Acquisition Time) contribute directly to the CTDIvol (mGy) and the DLP $\left(m G y^{*} \mathrm{~cm}\right)$, from which the ED is computed. This approach is consistent with Sun and $\mathrm{Ng}$ [24], who recommended the assessment of radiation exposure of CCTA by use of DLP $\left(\mathrm{mGy}^{\star} \mathrm{cm}\right)$ and CTDIvol (mGy). An increase in the scan range of $1 \mathrm{~cm}$ was associated with an increase in the DLP of approximately $5 \%$, and thus corresponding increases in the ED and LAR [25]. In patients undergoing CABG CTA, the larger scan range increased the organ dose and ED. In the current study, 
the ED for CABG CTA was $15.35 \pm 2.428 \mathrm{mSv}$, which was lower than the $16.42 \mathrm{mSv}$ in a recent study conducted by Hosseini Nasab et al. [19].

Cancer risk due to radiation exposure from a single cardiac imaging test depends on age (higher risk with younger age at exposure) and sex (greater for women) [14,24,25]. Consequently, an optimal strategy is to perform CCTA with the lowest possible exposure to radiation [26]. A study reported by Coles et al. [27] revealed that radiation dose and attendant risk associated with CCTA versus selective diagnostic coronary angiography in the same patients were $14 \mathrm{mSv}$ and $6 \mathrm{mSv}$, respectively. In disagreement with our results, Hirai et al [28] reported higher retrospectively ECG-gated CCTA doses (21 mSv for males and $18 \mathrm{mSv}$ for females). Huang et al [29] reported even higher doses ( 27.7 for males and 23.6 for females). A study conducted by Einstein et al. [30] on CCTA examination performed with a 16-slice MDCT revealed that the mean risk of death from cancer was approximately 1 in 1900. Another study conducted by Einstein et al. [25] on CCTA performed with a 64slice MDCT revealed that the mean risk of death from cancer varied from 1 in 143 for a 20-year-old woman to 1 in 3261 for an 80-year-old man. It is estimated that effective doses of CCTA may reach as high as $30 \mathrm{mSv}$ if no dose-saving strategy is applied, thus, increasing the potential risk of associated radiation-induced malignancy [31].

The LAR of cancer incidence and mortality in adult patients for all cancers is greater in females than in males (1:1516 female vs. 1:1762 male). Further, the LAR of cancer incidence and mortality decreases with age $(r=0.718, P<0.001)$, consistent with established relationships between radiosensitivity and age [21]. A study by Faletra et al. [32] reported ranges from approximately $1: 300$ to $1: 1800$ for exposure from retrospective ECG-gating CCTA. Therefore, CCTA should be used particularly cautiously for females in cardiac disease evaluation [25].

To put the dose estimates in a context that patients and physicians can readily understand, the ED for CABG CTA was compared with the effective doses for the two most common conventional radiology studies: a frontal and lateral chest radiography series (ED of $0.1 \mathrm{mSv}$ and equal to 10 days natural background radiation); and a screening mammography series (including 2 views of each breast, ED of $0.42 \mathrm{mSv}$ and equal to 7 weeks natural background radiation) [14]. Our comparison of organ-specific doses demonstrated that CABG CTA delivers a dose to the lung that is approximately equivalent to 51 chest radiography series and 72 weeks natural background radiation (5.04 mSv lung dose for CABG CTA vs 0.10 mSv lung dose for a frontal and lateral chest radiograph). The dose to the breast is equivalent to approximately 11 mammography studies and 77 weeks natural background radiation $(4.57 \mathrm{mSv}$ female breast dose for CABG CTA vs $0.42 \mathrm{mSv}$ breast dose for a mammography series). Concerning the total whole-body ED (15.35 mSv), CABG CTA is equivalent to 154 chest radiography series and 37 mammography studies, corresponding to approximately 4.3 and 5-years natural background radiation, respectively.

There are limitations in the estimation of doses and cancer risks in this study. Our results may be underestimations, because doses simulated using ImPACT have been reported by Groves et al. to be about 15\% lower than those measured by using thermoluminescent detectors directly [33]. This underestimation has been attributed to differences between the phantoms used in creating IMPACT and those used in the work of Groves et al. Because the ImPACT results are used to determine organ doses for a standard-size person, differences in patient size and tissue composition can result in inconsistencies in the organ dose estimation. There are limitations in calculating the LAR of cancer incidence insofar as LARs were calculated based on the ED from the CABG CTA protocols used in our clinic. Hence there may be some variation in risks, depending on the protocols used across centers and in different countries. Even with these variations, the ED simulated using ImPACT are robust and have been reported widely in the literature [5,19,29,34-37].

\section{CONCLUSION}

Organs receive a significant radiation dose during CABG CTA procedures, thereby motivating the use of rigorous justification criteria and protocol optimization. Furthermore, CABG CTA is associated with a nonnegligible LAR of cancer. This risk varies markedly and is significantly greater for women and younger patients. Knowledge of ED and LAR helps to improve medical staff awareness of radiation exposure consequences and contributes to keeping the patient radiation dose as low as reasonably achievable. A national survey is highly recommended to establish a national diagnostic reference level for all CT examinations.

\section{ABBREVIATIONS}

CABG CTA: Coronary Artery Bypass Graft Computed
Tomography Angiography

Author contributions: All authors participated in idea formation, data gathering, data analysis and interpretation, manuscript drafting and revising. All contributors approved the manuscript and agreed with study publication.

Funding: This research received no specific grant from any funding agency in the public, commercial, or not-for-profit sectors.

Ethical statement: Ethical approval for this study was obtained from the Helsinki Committee, Gaza strip-Palestine.

Declaration of interest: The authors declared no conflict of interest concerning the research, authorship, and publication of this article.

\section{REFERENCES}

1. Wall BF. Ionising radiation exposure of the population of the United States: NCRP report No. 160. Radiat. Prot. Dosim 2009;136(2):136-8. https://doi.org/10.1093/rpd/ncp162

2. Raman SP, Johnson PT, Deshmukh S, Mahesh M, Grant KL, Fishman EK. CT dose reduction applications: Available tools on the latest generation of CT scanners. J. Am. Coll. Radiol 2013;10(1):37-41. https://doi.org/10.1016/j.jacr. 2012.06.025 PMid:23290672

3. Valentin J. Managing patient dose in multi-detector computed tomography (MDCT). ICRP Publication 102. Ann ICRP 2007;37(1):1-79. 
4. Brenner DJ, Hall EJ. Computed tomography-An increasing source of radiation exposure. N. Engl. J. Med 2007;357(22):2277-84.

https://doi.org/10.1056/nejmra072149 PMid:18046031

5. Nickoloff EL, Alderson PO. A comparative study of thoracic radiation doses from 64-slice cardiac CT. Br. J. Radiol 2007;80(955):537-44. https://doi.org/10.1259/bjr/34603706 PMid: 17704315

6. Johnson JN, Hornik CP, Li JS, et al. Cumulative radiation exposure and cancer risk estimation in children with heart disease. Circulation 2014;130(2):161-7. https://doi.org/ 10.1161/CIRCULATIONAHA.113.005425 PMid:24914037 PMCid:PMC4103421

7. Kim HY, Choi JH. How to utilize coronary computed tomography angiography in the treatment of coronary artery disease. J. Cardiovasc. Ultrasound 2015;23(4):204-8. https://doi.org/10.4250/jcu.2015.23.4.204 PMid:26755927 PMCid:PMC4707304

8. Barbero U, lannaccone M, d'Ascenzo F, et al. 64 Slicecoronary computed tomography sensitivity and specificity in the evaluation of coronary artery bypass graft stenosis: A meta-analysis. Int. J. Cardiol 2016; 216:52-7. https://doi.org/10.1016/j.ijcard.2016.04.156 PMid:27140337

9. Eisenberg C, Hulten E, Bittencourt MS, Blankstein R. Use of CT angiography among patients with prior coronary artery bypass grafting surgery. Cardiovasc. Diagn. Ther 2017;7(1):102-5. https://doi.org/10.21037/cdt.2016.11.08 PMid:28164019 PMCid:PMC5253442

10. Di Lazzaro D, Crusco F. CT angio for the evaluation of graft patency. J. Thorac. Dis 2017;9(S4):S283-S288. https://doi.org/10.21037/jtd.2017.03.111 PMid:28540071 PMCid:PMC5422671

11. Wiest PW, Locken JA, Heintz PH, Mettler F. CT scanning: A major source of radiation exposure. Semin. Ultrasound CT MR 2002;23(5):402-10. https://doi.org/10.1016/S08872171(02)90011-9

12. Hausleiter J, Meyer T, Hadamitzky M, et al. Radiation dose estimates from cardiac multislice computed tomography in daily practice. Circulation 2006;113(10):1305-10. https://doi.org/10.1161/CIRCULATIONAHA.105.602490 PMid:16520411

13. Hunold P, Vogt FM, Schmermund A, et al. Radiation exposure during cardiac CT: Effective doses at multidetector row CT and electron-beam CT. Radiology 2003; 226(1):145-52. https://doi.org/10.1148/radiol.2261011365 PMid:12511683

14. Smith-Bindman R, Lipson J, Marcus R, et al. Radiation dose associated with common computed tomography examinations and the associated lifetime attributable risk of cancer. Arch. Intern. Med 2009;169(22):2078-86. https://doi.org/10.1001/archinternmed.2009.427 PMid:20008690 PMCid:PMC4635397

15. Van der Molen AJ, Schilham A, Stoop P, Prokop M, Geleijns J. A national survey on radiation dose in $\mathrm{CT}$ in The Netherlands. Insights into Imaging 2013;4(3):383-90. https://doi.org/10.1007/s13244-013-0253-9 PMid:23673455 PMCid:PMC3675255

16. Streffer C. The ICRP 2007 recommendations. Radiat. Prot. Dosim 2007;127(1-4):2-7. https://doi.org/10.1093/rpd/ ncm246 PMid:17933786
17. McCollough $\mathrm{CH}$, Christner JA, Kofler JM. How effective is effective dose as a predictor of radiation risk? AJR Am. J. Roentgenol 2010;194(4):890-6. https://doi.org/10.2214/ AJR.09.4179 PMid:20308487

18. Pradhan AS, Kim JL, Lee JI. On the use of "effective dose" (E) in medical exposures. J. Med. Phys 2012;37(2):63-5. https://doi.org/10.4103/0971-6203.94739 PMid:22557794 PMCid:PMC3339144

19. Hosseini Nasab SMB, Deevband MR, Shabestani-Monfared A, Amoli SAH, Feyzabad SHF. Organ equivalent dose and lifetime attributable risk of cancer incidence and mortality associated with cardiac CT angiography. Radiat. Prot. Dosim 2020;189(2):213-23. https://doi.org/10.1093/rpd/ ncaa033 PMid:32195547

20. Mansour HH, Alajerami YS, Najim AA. Coronary computed tomography angiography versus invasive coronary angiography: medical staff perceptions and diagnostic interest in Gaza-Palestine. Ir J Med Sci. 2021;190(2):567-75. https://doi.org/10.1007/s11845-020-02376-3 PMid:32978639

21. Council NR. Health risks from exposure to low levels of ionizing radiation: BEIR VII Phase 2. (National Academies Press) (2006).

22. Brenner DJ, Elliston CD, Hall EJ, Berdon WE. Estimated risks of radiation-induced fatal cancer from pediatric CT. AJR Am. J. Roentgenol 2001;176(2):289-96. https://doi.org/ 10.2214/ajr.176.2.1760289 PMid:11159059

23. Huda W, Schoepf UJ, Abro JA, Mah E, Costello P. Radiationrelated cancer risks in a clinical patient population undergoing cardiac CT. AJR Am. J. Roentgenol 2011;196(2):W159-W165.

https://doi.org/10.2214/ajr.10.4981 PMid:21257857

24. Sun Z, Ng K. Prospective versus retrospective ECG-gated multislice CT coronary angiography: A systematic review of radiation dose and diagnostic accuracy. Eur. J. Radiol 2012;81(2):e94-e100.

https://doi.org/10.1016/j.ejrad.2011.01.070 PMid:21316887

25. Einstein AJ, Henzlova MJ, Rajagopalan S. Estimating risk of cancer associated with radiation exposure from 64-Slice computed tomography coronary angiography. JAMA 2007;298(3):317-23.

https://doi.org/10.1001/jama.298.3.317 PMid:17635892

26. Neglia D, Rovai D, Caselli C, et al. Detection of significant coronary artery disease by noninvasive anatomical and functional imaging. Circulation 2015;8(3):1-10. https://doi.org/10.1161/circimaging.114.002179 PMid:25711274

27. Coles DR, Smail MA, Negus IS, et al. Comparison of radiation doses from Multislice computed tomography coronary angiography and conventional diagnostic angiography. J. Am. Coll. Cardiol 2006;47(9):1840-5. https://doi.org/ 10.1016/j.jacc.2005.11.078 PMid:16682310

28. Hirai N, Horiguchi J, Fujioka C, et al. Prospective versus retrospective ECG-gated 64-Detector coronary CT angiography: Assessment of image quality, stenosis, and radiation dose. Radiology 2008;248(2):424-30. https://doi.org/10.1148/radiol.2482071804 PMid:18574140

29. Huang B, Li J, Law MW, Zhang J, Shen Y, Khong PL. Radiation dose and cancer risk in retrospectively and prospectively ECG-gated coronary angiography using 64slice multidetector CT. Br. J. Radiol 2010;83(986):152-8. https://doi.org/10.1259/bjr/29879495 PMid:20139263 PMCid:PMC3473541 
30. Einstein A, Sanz J, Dellegrottaglie S, et al. Radiation dose and cancer risk estimates in 16-slice computed tomography coronary angiography. J. Nucl. Cardiol 2008;15(2):232-40.

https://doi.org/10.1016/j.nuclcard.2007.09.028 PMid:18371595 PMCid:PMC2397551

31. Xu L, Zhang Z. Coronary CT angiography with low radiation dose. Int. J. Cardiovasc. Image 2010;26(S1):17-25. https://doi.org/10.1007/s10554-009-9576-5 PMid:20058080

32. Faletra FF, D'Angeli I, Klersy C, et al. Estimates of lifetime attributable risk of cancer after a single radiation exposure from 64-slice computed tomographic coronary angiography. Heart 2010;96(12):927-32. https://doi.org/ 10.1136/hrt.2009.186973 PMid:20538668

33. Groves AM, Owen KE, Courtney HM, et al. 16-detector multislice CT: Dosimetry estimation by TLD measurement compared with Monte Carlo simulation. Br. J. Radiol 2004;77(920):662-5. https://doi.org/10.1259/bjr/48307881 PMid:15326044
34. Brenner DJ. Radiation risks potentially associated with low-dose CT screening of adult smokers for lung cancer. Radiology 2004;231(2):440-5. https://doi.org/10.1148/ radiol.2312030880 PMid: 15128988

35. Sawyer LJ, Starritt HC, Hiscock SC, Evans MJ. Effective doses to patients from CT acquisitions on the GE Infinia Hawkeye: A comparison of calculation methods. Nucl. Med. Commun 2008;29(2):144-9. https://doi.org/10.1097/mnm. 0b013e3282f258ef PMid:18094636

36. Myronakis M, Perisinakis K, Tzedakis A, Gourtsoyianni S, Damilakis J. Evaluation of a patient-specific Monte Carlo software for CT dosimetry. Radiat. Prot. Dosim 2009;133(4):248-55. https://doi.org/10.1093/rpd/ncp051 PMid:19329513

37. Kim KP, Lee J, Bolch WE. CT dosimetry computer codes: Their influence on radiation dose estimates and the necessity for their revision under new ICRP radiation protection standards. Radiat. Prot. Dosim 2011;146(13):252-5. https://doi.org/10.1093/rpd/ncr163 PMid: 21515617 